\title{
Parents' Personality Disorders as Predictor of Substance Use Disorder in Children and Adolescents
}

\author{
Mohammad Reza Mohammadi, MD¹, Seyed Kaveh Hojjat, MD²,3*, Seyed Ali Mostafavi, PhD' , Ali Khaleghi, PhD', Zahra Hooshyari, \\ PhD ${ }^{1}$, Nastaran Ahmadi, PhD $^{4}$, Faezeh Kaviyani, MSc $^{3}$, Mina Norozi Khalili, MD $^{3}$ \\ ${ }^{1}$ Psychiatry and Psychology Research Center, Roozbeh Hospital, Tehran University of Medical Sciences, Tehran, Iran \\ ${ }^{2}$ Division of Sleep Medicine, Psychiatry and Behavioral Sciences Research Center, Mashhad University of Medical Sciences, \\ Mashhad, Iran \\ ${ }^{3}$ Addiction and Behavioral Sciences Research Center, North Khorasan University of Medical Sciences, Bojnurd, Iran \\ ${ }^{4}$ Yazd Cardiovascular Research Center, Shahid Sadoughi University of Medical Sciences, Yazd, Iran
}

\begin{abstract}
Background: This study investigated how the parents' personality disorders may be related to substance use disorder in children and adolescents.

Methods: The study was a cross-sectional study in which 28,540 children and adolescents (aged 6 to 18 years) and their parents participated between 2015 and 2016. The diagnosis of substance use was made using the Kiddie Schedule for Affective Disorders and Schizophrenia--Present and Lifetime Version (K-SADS-PL) interview and the personality disorders were assessed using Millon Clinical Multiaxial Inventory - Third Edition (MCMI-III). The parents were also surveyed for their personality assessed with MCMI. Results: The results showed that the paranoid personality disorder in father (odds ratio $[\mathrm{OR}]=8.34,95 \% \mathrm{Cl}, P=0.042$ ) and borderline personality disorder in mother $(\mathrm{OR}=4.6,95 \% \mathrm{Cl}, P=0.049)$ increase the chance of substance use in children. Conclusion: The findings suggest that in designing preventive programs for substance use, the personality characteristics of the parents need to be taken into account.

Keywords: Adolescent, Child, Personality Disorders, Substance Use Disorder

Cite this article as: Mohammadi MR, Hojjat SK, Mostafavi SA, Khaleghi A, Hooshyari Z, Ahmadi N, et al. Parents' personality disorders as predictor of substance use disorder in children and adolescents. Arch Iran Med. 2021;24(6):478-486. doi: 10.34172/ aim.2021.69
\end{abstract}

Received: February 10, 2020, Accepted: September 16, 2020, ePublished: June 1, 2021

\section{Introduction}

Using substance in adolescents is a biosocial and cultural phenomenon and a crisis for the modern societies. ${ }^{1} \mathrm{~A}$ study in the United States in 2016 showed that $17.2 \%$ of the 8 th grade students, $33.7 \%$ of the 10 th grade students and $48.3 \%$ of the 12 th grade students had used illegal drugs. ${ }^{2}$ The studies conducted in Iran have reported the prevalence of using tobacco at $12 \%$, smoking experience at $16.9 \%$, drug experience at $18.2 \%$ and substance use at $4.4 \%$ in students. ${ }^{3-5}$ The growing prevalence of drug use in adolescents is concerning ${ }^{6}$ and the scientific evidence suggests that starting to use different types of substances during adolescence increases the chance of dependency. ${ }^{7-9}$ Early use of substances also increases the susceptibility to drug-related disorders, ${ }^{10}$ which can be a strong predictor of academic failure, brain impairment, risky sexual behavior, unwanted pregnancy in adolescents, depression, attempting suicide and criminal activities. ${ }^{11,12}$

Given the importance of substance use in adolescents, it seems that understanding the related risk factors is necessary for its treatment and prevention. Studies show that factors such as family, society, personality, interpersonal interactions, environmental and situational factors can predict the risky behaviors and substance use in children and adolescents..$^{13,14}$
Family is an important factor in the development and prevention of substance use in adolescents. The growing literature has also emphasized the influence of the family both theoretically and empirically. ${ }^{15,16}$ The assumptions of social learning theory suggest that the family attitudes and parents' behaviors are related to substance use in children. ${ }^{17}$ The system family therapy as a psychological approach also looks for the origins of psychiatric disorders and disorganized behaviors in the family. ${ }^{18}$ Furthermore, various studies have confirmed the effect of inheritance on the formation of certain behaviors including substance use. ${ }^{19}$ Accordingly, the personality characteristics of parents can play a role in substance use in children and adolescents. The parenting models have highlighted the role of parental characteristics in the formation of children's behaviors. ${ }^{20}$ In this field, studies have shown that there is a relationship between parents' mental and personality disorders and children's behavioral and mental problems. ${ }^{21,22}$ Several studies suggest that parental support, supervision, and responsibility are correlated with substance use in children and adolescents. ${ }^{23,24}$ However, there is limited information on the association between substance use in children and adolescents and personality disorders in parents. ${ }^{25}$ The current study intends to investigate the parents' personality traits and

*Corresponding Author: Seyed Kaveh Hojjat, MD; Hore-Ameli Street, Ebne-Sina psychiatric hospital, Psychiatry and Behavioral sciences research center, Mashh had, Iran. Tel: +98- 5137002345; Email: S.kavehhojjat1@gmail.com 
disorders as predictors of substance use in children and adolescents.

\section{Materials and Methods \\ Sampling}

This study used data from a national, cross-sectional project in Iran that aimed at investigating the psychiatric disorders of children and adolescents and how they are related to parental personality. ${ }^{26,27}$ The sampling method was multi-stage clustering. Totally, 30532 children and teenagers from 29 provinces participated in this study. Participants were selected from the main cities and rural populations of the provinces. To select the sample, clusters were created. The urban and rural locations constituted the clusters, which amounted to 170 clusters. Next, within each cluster, blocks were formed to ensure equal distribution of gender and age in the sample. Each block contained girls and boys from the three age groups; 6-9 (9804 people), 10-14 (9993 people), and 15-18 years (8743 people) (see Table 1 for the number of children and adolescents in each age group). To form a block, individuals from each age group and gender were assigned to a block. In other words, each block included 6 individuals (boys and girls from three age groups). After screening the children and adolescents, 227 individuals were found addicted to different types of substances (totally, 37 blocks of 6 individuals + a block of 5 individuals). The parents of these children and adolescents and those of the nonaddicted (totally 30255 children and adolescents) were surveyed in terms of personality disorders to estimate how parents' personality disorders can predict substance use disorder in children and adolescents. During the study, 1715 individuals in the non-addicted group quit or were removed from the study. Hence, a total number of 28540 non-addicted children and adolescents (totally, 4756 blocks of 6 individuals + a block of 4 individuals) remained in the study (see Table 1 for the statistics of the children and adolescents and Table 2 for various types of substances used by the children and adolescents).

The inclusion criteria were being within the age groups of 6-9, 10-14, and 15-18 years, willingness to participate (permitted by parents), signing the informed consent form (by parents), and fully completing the K-SADS-PL and Millon Clinical Multiaxial Inventory - Third Edition (MCMI-III) (completed by parents). The exclusion criteria were not having any parents and unwillingness to continue the study.

\section{Data Collection}

The actual data were drawn from a national study on the prevalence of substance use disorder among Iranian children and adolescents in 2016. To carry out the national study, eight clinical psychologists were selected from each province. These psychologists were trained how to administer Kiddie Schedule for Affective Disorders and Schizophrenia--Present and Lifetime Version (K-SADSPL) that was installed on Android tablets. According to the protocol, psychologists identified the eligible children and adolescents and recorded their demographic information. Before collecting data, consents were obtained from the children's families. The K-SADS-PL was then used by the clinical psychologists to interview the participants and

Table 1. Socio-demographic Characteristics of the Children and Adolescents

\begin{tabular}{lccc}
\hline \multirow{2}{*}{ Socio-demographic Characteristics } & Total & With Substance Use Disorders & $\begin{array}{c}\text { Without Substance Use Disorders } \\
\text { (Comparison Group) }\end{array}$ \\
\cline { 2 - 4 } & $\boldsymbol{n}(\%)$ & $\boldsymbol{n}(\%)$ & $\boldsymbol{n}(\%)$ \\
\hline Boy & $13936(48.8)$ & $193(69.6)$ & $15115(53)$ \\
\hline Girl & $14604(51.2)$ & $84(30.4)$ & $13425(47)$ \\
\hline $6-9$ & $9804(34.4)$ & $53(19.1)$ & $4861(17)$ \\
\hline $10-14$ & $9993(35)$ & $67(24.3)$ & $7116(25)$ \\
\hline $15-18$ & $8743(30.6)$ & $157(56.6)$ & $16563(58)$ \\
\hline
\end{tabular}

Table 2. Status of Substance Abuse in Children and Adolescents

\begin{tabular}{lcc}
\hline Drugs & n & Percent \\
\hline Cannabis (Marie, Pot, Hash) & 61 & 22 \\
\hline Stimulants (speed, amphetamine, crystal, slimming pills) & 36 & 13 \\
$\begin{array}{l}\text { Hypnotic/sedative/antianxiety drugs (barbiturates, benzodiazepines, diazepam, oxazepam, lorazepam, alprazolam } \\
\text { (Xanax)) }\end{array}$ & 77 & 28 \\
Heroin & 14 & 5 \\
Opioids (opium/sheere/heroin/morphine/methadone/codeine/pethidine) & 24 & 8.5 \\
PCP (phencyclidine)/angel power & 13 & 4.7 \\
Hallucinogenic material (LSD/Acid/Mescaline/Peyote/Mushroom & 20 & 7.2 \\
Solvents or inhalants materials (glue/gasoline/chloroform/ether/colorants) & 8 & 2.9 \\
Others (prescribed drugs/nitrous oxide/ecstasy/methylene/amphetamine, etc.) & 24 & 8.7 \\
\hline
\end{tabular}


their parents. As the first draft of this research's proposal and the data collection was conducted in year 2015, the K-SADS-Pl used was based on DSM IV. Due to the fact that we considered four criteria for diagnosing substance use disorder, it can be argued that the substance use disorder in the current study was in the range of moderate intensity in terms of DSM V criteria. To assess parental personality disorders and personality traits, parents were instructed to complete the MCMI. For more information on the method of data collection, it should be noted that assessors of parental personality characteristics were blinded to the addiction status of children and adolescents. To assure proper data collection, the psychologists were frequently monitored through repeated phone calls to remind them of the proper assessment procedure and up-to-date report of data collection. The missing data were managed through pairwise deletion. The main confounder in the current study was the education status of parents, which was taken into account by calculating the adjusted OR. The response rate was calculated by dividing the number of completed surveys by the number of participants which was $91.33 \%$ for K-SADS-PL and $88.26 \%$ for MCMI-III. Data collection in the field lasted about 6 months.

\section{Kiddie-SADS-Present and Lifetime Version}

$\mathrm{K}-\mathrm{SADS}-\mathrm{PL}$ is a semi-structured interview designed to assess the current and past episodes of mental illnesses in children and adolescents. It includes five diagnostic categories: (1) mood disorders such as depression disorders (major depression, dysthymia), mania, and hypomania; (2) psychotic disorders; (3) anxiety disorders such as social phobia, agoraphobia, specific phobia, obsessivecompulsive disorder, separation anxiety disorder, general anxiety disorder, panic disorder, and post-traumatic stress disorder; (4) behavioral disorders such as ADHD, conduct disorder, and oppositional defiant disorder; (5) substance use, tic disorders, eating disorders and elimination disorders. ${ }^{28}$ This semi-structured interview is based on Diagnostic and Statistical Manual of Mental Disorders, 4th Edition. The interview started with questions about demographic information. In addition, information was obtained on previous psychiatric complaints and problems. ${ }^{29}$

The K-SADS, Farsi version has excellent test-retest and inter-rater validity. In addition, the sensitivity and specificity of the Persian version of K-SADS have been very high. ${ }^{30}$

\section{Millon Clinical Multiaxial Inventory - Third Edition}

Millon was published in 1994 and is one of the most important instruments for assessing the clinical symptoms of Axis I and Axis II of DSM-IV. ${ }^{31}$ Million-3rd edition is the latest version of Millon's clinical multiaxial questionnaire. The questionnaire is a self-evaluative psychological assessment tool that includes 175 items. The items compose 14 personality pattern scales and 10 clinical syndrome scales on a yes/no basis. ${ }^{32}$ Blais et al reported a reliability index of 0.89 for personality scales and 0.91 for clinical syndrome scales. They calculated the total reliability of the inventory through internal consistency and testretest measures and reported adequate reliability. ${ }^{33}$ The completion of the Millon Clinical Multiaxial Inventory takes 20 to 25 minutes. ${ }^{31}$

Sharifi et al reported that the reliabilities of different scales of the MCMI-III are between 0.82 and 0.98 . It can be concluded that the Persian version of the Millon Clinical Multiaxial Inventory has adequate reliability and validity; so, it can be used safely in Iranian samples. ${ }^{34}$

\section{Data Analysis}

The collected data from all provinces were screened for any incomplete data. In this study, the odds ratio (OR and 95\% CI) was used to determine the predictors of substance use in children and adolescents based on the personality disorders and personality traits of parents. To control for the effects of confounders, adjusted OR was taken into account.

\section{Results}

The total number of fathers participating in this study was 18081 with an average age of $43.29 \pm 7.62$ years, and the total number of mothers was 26143 with an average age of $38.09 \pm 6.62$ years. Based on the results of K-SADSPL, 277 children and adolescents were identified as substance users. When the parents of the substance users (146 fathers and 216 mothers) completed the MCMI-III, logistic regression was run to understand how well the personality traits and disorders of the parents predict the substance use in children and adolescents. The demographic characteristics of the parents including age, education, and occupation are presented in Table 3.

\section{Personality Disorders of the Parents as Predictors of Substance Use in Children and Adolescents}

In this study, regression models were used to investigate how parents' personality disorders such as schizotypal, borderline and paranoid disorders can predict substance use in children and adolescents.

Odds Ratios of Substance Use in Children and Adolescents According to the Personality Disorder of the Fathers

Odds ratios (ORs) indicating the relationship between substance use in children and adolescents and personality disorders in fathers are presented in Table 4.

The results of regression analysis indicate that paranoid personality disorder in fathers is significantly correlated with substance use in children and adolescents $(P=0.04)$. Those whose fathers had paranoid personality disorder were 8 times more likely to use substance than other children and adolescents $(\mathrm{OR}=8.34, \mathrm{CI}=1.09-64)$.

Odds Ratios of Substance Use in Children and Adolescents According to the Personality Disorder of the Mothers The results (Table 5) showed a significant correlation 
Table 3. Distribution of Demographic Characteristics of Parents

\begin{tabular}{|c|c|c|c|c|}
\hline & Demographic & Variables & $\begin{array}{l}\text { For addicted children } \\
\text { No. }(\%)\end{array}$ & $\begin{array}{c}\text { For non-addicted children } \\
\text { No. }(\%)\end{array}$ \\
\hline \multirow{17}{*}{ Mothers } & \multirow{8}{*}{ Educations } & Illiterate & $157(44.7)$ & $2545(9.9)$ \\
\hline & & Primary school & $99(28.2)$ & $4189(16.2)$ \\
\hline & & Guidance and high school & $70(19.9)$ & $6121(23.7)$ \\
\hline & & Diploma & $17(4.8)$ & $6037(23.4)$ \\
\hline & & Bachelor & $3(0.9)$ & $4284(16.6)$ \\
\hline & & Master's or higher & $1(0.3)$ & $2286(8.9)$ \\
\hline & & Missing & $4(1.1)$ & $327(1.3)$ \\
\hline & & Total & $351(100)$ & $25789(100)$ \\
\hline & \multirow{9}{*}{ Jobs } & Housewife & $216(61.5)$ & $14422(55.9)$ \\
\hline & & Laborers & $125(35.6)$ & $4120(16)$ \\
\hline & & Tradesman & $1(0.3)$ & $3776(14.6)$ \\
\hline & & Retired & $3(0.9)$ & $3777(14.6)$ \\
\hline & & Employee & $3(0.9)$ & $4405(17)$ \\
\hline & & Teacher & $0(0)$ & $4185(16.2)$ \\
\hline & & Faculty member & $0(0)$ & $3717(14.4)$ \\
\hline & & Missing & $3(0.9)$ & $279(1)$ \\
\hline & & Total & $351(100)$ & $25789(100)$ \\
\hline \multirow{18}{*}{ Fathers } & \multirow{8}{*}{ Educations } & Illiterate & $123(60.6)$ & $1836(10.3)$ \\
\hline & & Primary school & $38(18.7)$ & $2816(15.8)$ \\
\hline & & Guidance and high school & $7(3.4)$ & 3449 (19.3) \\
\hline & & Diploma & $13(6.4)$ & $4027(22.5)$ \\
\hline & & Bachelor & $2(1)$ & $3406(19)$ \\
\hline & & Masters or higher & $0(0)$ & $2104(11.8)$ \\
\hline & & Missing & $2(1)$ & $240(1.3)$ \\
\hline & & Total & $203(100)$ & $17878(100)$ \\
\hline & \multirow{10}{*}{ Jobs } & Unemployed & 75 (36.9) & $1392(7.8)$ \\
\hline & & Laborer & $95(46.8)$ & $6043(33.8)$ \\
\hline & & Farmer & $6(3)$ & $1429(8)$ \\
\hline & & Businessman & $3(1.5)$ & $1416(8)$ \\
\hline & & Retired & $6(3)$ & $1671(9.3)$ \\
\hline & & Public sector & $13(6.4)$ & 3166 (17.7) \\
\hline & & Teacher & $3(1.5)$ & $1390(7.8)$ \\
\hline & & Faculty member & $0(0)$ & $1161(6.5)$ \\
\hline & & Missing & $2(1)$ & $210(1.2)$ \\
\hline & & Total & $203(100)$ & $17878(100)$ \\
\hline
\end{tabular}

Table 4. Odds Ratios $(95 \% \mathrm{Cl}$ ) for Children and Adolescents with Substance Use Based on Father's Severe Personality Disorders

\begin{tabular}{lccc}
\hline Severe Personality Disorders & Diagnostic Labels & Univariate OR $(\mathbf{C l ~ 9 5 \% )}$ & Multivariate Adjusted OR (CI 95\%) \\
\hline \multirow{3}{*}{ Schizotypal } & No & - & - \\
\cline { 2 - 4 } & At risk & $2.1(0.8-5.6)$ & - \\
\cline { 2 - 4 } & Yes & - & - \\
Borderline & No & - & $1.5-3.3)$ \\
& At risk & $1.4(0.4-4.3)$ & $1.9(0.3-3.2)$ \\
& Yes & $2.2(0.3-15.6)$ & - \\
Paranoid & No & - & - \\
& At risk & - & $7.1(1.5-22) *$ \\
\hline
\end{tabular}

Adjusted OR, adjusted for education status of parents.

*Significant at the level $\leq 0.05$. 
Table 5. Odds Ratios $(95 \% \mathrm{Cl})$ for Children and Adolescents with Substance Use based on Mother's Severe Personality Disorders

\begin{tabular}{lccc}
\hline Severe Personality Disorders & Diagnostic Labels & Univariate OR (Cl 95\%) & Multivariate Adjusted OR (CI 95\%) \\
\cline { 2 - 3 } Schizotypal & No & - & - \\
& At risk & $0.5(0.0-10)$ & $0.5(0.2-8.2)$ \\
& Yes & $1.6(0.0-73.9)$ & $1.4(0.0-52.6)$ \\
Borderline & No & - & - \\
& At risk & $0.5(0.1-4.5)$ & $0.3(0.0-2.2)$ \\
Paranoid & Yes & $4.6(1-21.1)$ & $3.2(1.2-17.1)$ \\
& No & - & - \\
& At risk & $1.5(0.2-11.3)$ & - \\
\hline
\end{tabular}

Adjusted OR, adjusted for education status of parents.

between substance use and borderline personality disorder in mothers $(P=0.049)$. Therefore, children and adolescents whose mothers have borderline personality disorder are approximately 5 times more likely to be at risk of substance use than other children and adolescents (OR $=4.6,95 \% \mathrm{CI}=1-21.06)$.

\section{Odds Ratios of Substance Use in Children and Adolescents According to the Personality Traits of the Fathers}

The results of regression analysis in Table 6 show that there is a significant correlation between schizoid personality disorder in fathers and substance use in children and adolescents $(P=0.01)$. Those whose fathers suffer from schizoid personality disorder are 16 times more likely to be at the risk of substance use $(\mathrm{OR}=15.55, \mathrm{CI}=1.9-127.1)$. As seen in Table 6, there is also a significant relationship between the presence of histrionic personality disorder in fathers and substance use in children and adolescents $(P=$ $0.008)$. The observed odds ratio $(\mathrm{OR}=0.47, \mathrm{CI}=0.27-82)$ shows that those whose fathers have histrionic personality disorder have a lower chance of abusing substance.

\section{Odds Ratios of Substance Use in Children and Adolescents According to the Personality Traits of the Mothers}

Regression analysis indicated that substance use in children and adolescents is significantly related to histrionic disorder $(P=0.005)$, sadistic disorder $(P=$ $0.004)$, and obsessive compulsive disorder $(P=0.012)$ in mothers (Table 7). As seen in Table 7, individuals whose mothers suffer from histrionic personality disorder $(\mathrm{OR}=0.39, \mathrm{CI}=0.20-0.76)$ and obsessive compulsive disorder $(\mathrm{OR}=0.53, \mathrm{CI}=0.32-0.87)$ are less likely to use substances. In addition, those whose mothers suffer from sadistic personality are 16 times more likely to use substances $(\mathrm{OR}=16.3, \mathrm{CI}=2.44-108.7)$.

\section{Discussion}

The results showed that paranoid and schizoid personalities in fathers and borderline and sadistic personality in mothers can be predictors of substance use in children and adolescents. Furthermore, it was revealed that histrionic personality disorder in parents (both father and mother) and obsessive compulsive disorder in mother can lower the chance of substance use by children and adolescents.

Children and adolescents whose fathers suffered from paranoid personality disorder were 8 times more likely to use substances. No empirical study on the relationship between parents' paranoid personality and substance use in children was found by the researchers to compare and contrast our findings. However, a study by Wilson and Durbin indicated that parents with paranoid personality disorder are less responsible towards their children. ${ }^{35} \mathrm{On}$ the other hand, Dessaulles et al pointed to the intimacy between parents and children as a factor for preventing substance use in children. ${ }^{36} \mathrm{~A}$ study by Hair et al. showed that good relationship between children and parents can promote children's mental health and reduce juvenile delinquency. ${ }^{37}$ The people with paranoid personality disorder are highly sensitive, suspicious and aggressive. ${ }^{38}$ Accordingly, parents with paranoid personality disorder would make the living environment insecure and full of tensions for children, a situation that may make the children susceptible to alcohol and substance use.

According to the results, children and adolescents whose mothers had borderline personality disorder were 5 times more likely to be at risk of substance and alcohol use. Barno et al found that children and adolescents whose mothers suffered from borderline personality had difficulty in controlling impulse and aggression and were prone to delinquency. These children had lower selfesteem than children who had depressed mothers, mothers with disorders in cluster $\mathrm{c}$, or mothers with no disorder. ${ }^{39}$ Nickell et al found that insecure connection between a child and a mother suffering from borderline personality can provide the ground for behavioral problems later in the life of the child. ${ }^{40}$ A study by Branstetter et al also supports the role of a supportive mother in preventing substance use in children. ${ }^{24}$ The present study also found that children whose fathers had schizoid personality were 16 times more likely to use substance and alcohol. People with schizoid personality are not willing to engage in social interactions and are apathetic. ${ }^{38}$ Parker's study has shown that parents who were more successful in protecting their 
Table 6. Odds Ratios $(95 \% \mathrm{Cl})$ for Children and Adolescents with Substance Use Based on Father Father's Clinical Pattern of Personality Disorders

\begin{tabular}{|c|c|c|c|}
\hline Clinical Personality Disorders & Diagnostic Labels & Univariate OR (Cl 95\%) & Multivariate Adjusted OR (Cl 95\%) \\
\hline \multirow{3}{*}{ Schizoid } & No & - & - \\
\hline & At risk & $0.7(0.1-5)$ & $0.5(0.2-3.6)$ \\
\hline & Yes & $15.6(1.9-127.1)^{* *}$ & $12.8(2.6-88.4)^{* *}$ \\
\hline \multirow{3}{*}{ Avoidant } & No & Base line & - \\
\hline & At risk & $1.6(0.6-5.2)$ & $1.2(1-3.2)$ \\
\hline & Yes & - & - \\
\hline \multirow{3}{*}{ Melancholic } & No & - & - \\
\hline & At risk & $2.8(1.5-5.3)^{* *}$ & $3.6(2.2-3.8)^{* *}$ \\
\hline & Yes & $1.4(0.5-3.7)$ & $1.9(0.9-3.4)$ \\
\hline \multirow{3}{*}{ Dependent } & No & Base line & \\
\hline & At risk & $3.5(1.3-9.6)^{*}$ & $3.9(2-6.6)^{*}$ \\
\hline & Yes & - & - \\
\hline \multirow{3}{*}{ Histrionic } & No & - & - \\
\hline & At risk & $0.6(0.4-.8)^{* *}$ & $0.9(0.6-1)^{* *}$ \\
\hline & Yes & $0.5(0.3-.8)^{* *}$ & $0.4(0.6-0.7)^{* *}$ \\
\hline \multirow{3}{*}{ Narcissistic } & No & - & - \\
\hline & At risk & $2.1(0.9-4.7)$ & $1.7(0.7-3.3)$ \\
\hline & Yes & - & - \\
\hline \multirow{3}{*}{ Anti-social } & No & - & - \\
\hline & At risk & $2.5(0.6-10.1)$ & $2(5.7-9.7)$ \\
\hline & Yes & - & - \\
\hline \multirow{3}{*}{ Sadistic } & No & & \\
\hline & At risk & $1.6(0.6-4.3)$ & $1.5(0.3-3.6)$ \\
\hline & Yes & - & - \\
\hline \multirow{3}{*}{ Obsessive compulsive } & No & - & - \\
\hline & At risk & $0.6(0.4-0.8)^{* *}$ & $0.3(0.3-0.7)^{* *}$ \\
\hline & Yes & $0.9(0.5-1.5)$ & $0.8(0.5-1.2)$ \\
\hline \multirow{3}{*}{ Negativistic } & No & - & - \\
\hline & At risk & $0.7(0.1-4.7)$ & $0.5(0.2-3.3)$ \\
\hline & Yes & $0.6(0.1-5.9)$ & $0.3(0.4-3.6)$ \\
\hline \multirow{3}{*}{ Masochistic } & No & - & \\
\hline & At risk & $2.5(1.1-5.8)^{*}$ & $2(1.4-4.3)^{*}$ \\
\hline & Yes & - & - \\
\hline
\end{tabular}

Adjusted OR, adjusted for education status of parents.

$*$ Significant at the level $\leq 0.05$.

$* *$ Significant at the level $\leq 0.01$

children from substance use felt more responsible towards their children. It seems that the lack of intimacy and support by the father in developmental stages of children increases the probability of high-risk behaviors such as alcohol and substance use in adolescence. ${ }^{23}$

Another finding of the study was that children with mothers suffering from sadistic personality were 16 times more likely to use substance and alcohol than other children. People with sadistic personality have been reported to show violent, humiliating, and aggressive behaviors towards others. ${ }^{38}$ Studies have shown that hostile behavior by parents and punishment by mother can hinder the development of prosocial development in children which can raise the risk of behavioral problems in children. Substance use by children of such mothers can be a defensive mechanism, especially when they are used by their loved ones. ${ }^{41,42}$

The results of the current study indicate that histrionic personality in parents (both fathers and mothers) can be a protective factor against substance use by children. In this regard, no empirical study was found, but given that people with histrionic personality exaggerate a lot when expressing emotions, it is quite possible that their exaggeration about negative effects of drug use (Iranian families regularly warn their children about drug use) could have acted as a protection against substance use by 
Table 7. Odds Ratios $(95 \% \mathrm{Cl})$ for Children and Adolescents with Substance Use Based on Mother's Clinical Pattern of Personality Disorders

\begin{tabular}{|c|c|c|c|}
\hline Clinical Personality Disorders & Diagnostic Labels & Univariate OR (CI 95\%) & Multivariate Adjusted OR (Cl 95\%) \\
\hline \multirow{3}{*}{ Schizoid } & No & Base line & - \\
\hline & At risk & $2.3(0.9-6.2)$ & $2.2(0.7-5.3)$ \\
\hline & Yes & - & - \\
\hline \multirow{3}{*}{ Avoidant } & No & Base line & - \\
\hline & At risk & $2(0.5-7.3)$ & $1.1(1.2-6.8)$ \\
\hline & Yes & $4.6(0.7-31.6)$ & $3.9(1-24.6)$ \\
\hline \multirow{3}{*}{ Melancholic } & No & Base line & - \\
\hline & At risk & $1.5(0.8-2.7)$ & $1.6(0.9-1.1)$ \\
\hline & Yes & $1.3(0.6-2.2)$ & $1.1(0.8-1.7)$ \\
\hline \multirow{3}{*}{ Dependent } & No & Base line & - \\
\hline & At risk & $1.5(0.5-4.7)$ & $1.9(0.7-4.2)$ \\
\hline & Yes & $1(0.2-6.3)$ & $0.7(0.7-4.3)$ \\
\hline \multirow{3}{*}{ Histrionic } & No & Base line & - \\
\hline & At risk & $0.6(0.3-0.9)^{*}$ & $0.4(0.3-0.8)^{*}$ \\
\hline & Yes & $0.4(0.2-0.8)^{* *}$ & $0.3(0.2-0.7)^{* *}$ \\
\hline \multirow{3}{*}{ Narcissistic } & No & Base line & - \\
\hline & At risk & $0.8(0.3-1.8)$ & $0.7(0.2-1.5)$ \\
\hline & Yes & - & - \\
\hline \multirow{3}{*}{ Anti-social } & No & Base line & - \\
\hline & At risk & $7.7(1-58)^{*}$ & $5.2(1.7-28.1)^{*}$ \\
\hline & Yes & - & - \\
\hline \multirow{3}{*}{ Sadistic } & No & Base line & - \\
\hline & At risk & $2.1(0.6-7.1)$ & $1.7(0.5-4.3)$ \\
\hline & Yes & $16.3(2.4-108.7)^{* *}$ & $11.7(2.9-63.9)^{* *}$ \\
\hline \multirow{3}{*}{ Obsessive compulsive } & No & Base line & - \\
\hline & At risk & $0.5(0.2-1)$ & $0.3(0.2-1.5)$ \\
\hline & Yes & $0.5(0.3-0.9)^{*}$ & $0.8(0.3-0.6)^{*}$ \\
\hline \multirow{3}{*}{ Negativistic } & No & Base line & - \\
\hline & At risk & $1.7(0.9-3.3)$ & $1.4(0.6-2.2)$ \\
\hline & & $2.4(0.5-10.6)$ & $2.1(0.5-7.5)$ \\
\hline \multirow{3}{*}{ Masochistic } & No & Base line & - \\
\hline & At risk & $1.4(0.5-3.7)$ & $1.2(0.2-3.3)$ \\
\hline & Yes & $0.7(0.0-29.2)$ & $0.5(0.0-19.7)$ \\
\hline
\end{tabular}

Adjusted OR, adjusted for education status of parents.

*Significant at the level $\leq 0.05$.

**Significant at the level $\leq 0.01$.

children. This conclusion requires further attention and scrutiny as it might work positively in Iranian families for the prevention of substance use by children.

According to the results of this study, obsessivecompulsive personality disorder in mothers was negatively associated with substance use in children. In this regard, various studies have supported the relationship between controlling, monitoring, and authoritative parenting styles and lower probability of drug use in adolescents. . $^{43,44}$ Wilson and Darwin found that parents, especially mothers, with obsessive-compulsive disorder tend to exert control over their children which may cause a lower chance of substance use in their children. ${ }^{40}$

In conclusion, the present study showed that some parental personality traits (schizoid, histrionic in fathers; histrionic, sadistic, and obsessive compulsive in fathers) and personality disorders (borderline in mothers; paranoid in fathers) correlate with substance use in children. Some studies have reported the coexistence of some characteristics such as hostility, aggression, forcefulness in parents and maladaptive and abnormal behaviors in children. ${ }^{25-27}$ One of the main criteria for all personality disorders is disturbance in interpersonal relationships. Therefore, the relationship between substance use in children and adolescents and personality disorders in their parents can be explained using theories of interpersonal relationships. The findings of this study can be helpful for identifying the causes of early substance 
use in children and adolescents and adopting appropriate preventive programs.

To collect data on substance use, the K-SADS interviews were carried out in the presence of parents. Accordingly, the cases of substance use identified in the current study could be extreme cases of substance use. Therefore, more accurate comparisons of individuals that never used substance and those who had experienced substance were not possible.

Most studies on substance use have focused on specific populations. ${ }^{1,6}$ However, the participants of the current study were from all ethnicities and educational backgrounds; hence, the findings have the potential to be generalized to the entire community. Most studies have mainly focused on adolescents, ${ }^{1,6}$ but in the present study, children and adolescents aged 6 to 18 years were the subjects of the study.

\section{Authors' Contribution}

MRM, SKH, SAM, AK And NA: Provincial implementation and data collection. ZH: Data analysis. MRM, SKH, FK and MNK: Writting the first draft of the manuscript. all authors provided critical comments on the manuscript.

\section{Conflict of Interest Disclosures}

Noting to declare.

\section{Ethical Statement}

All participants gave their informed consent. Also, the informed consent of adolescents over 15 years of age was given by themselves and their parents. This study was approved by the national institute for medical research development (NIMAD) ethics committee (the ethics code of IR.NIMAD.REC.1395.001 and grant number of 940906).

\section{Acknowledgements}

We thank all the psychologists and colleagues from all the provinces for their collaboration. We also thank the families and the children who participated in this study.

\section{References}

1. Johnston LD, O'Malley PM, Bachman JG, Schulenberg JE. Monitoring the Future National Survey Results on Drug Use, 1975-2008: Volume II: College Students and Adults Ages 19-50. Bethesda, MD: National Institute on Drug Abuse; 2009.

2. Miech RA, Johnston LD, O'Malley PM, Bachman JG, Schulenberg JE, Patrick ME. Monitoring the Future National Survey Results on Drug Use, 1975-2016: Volume I, Secondary School Students. Ann Arbor, Michigan: Institute for Social Research, The University of Michigan; 2017. Available at: http://monitoringthefuture.org/pubs. html\#monographs.

3. Babaei Heydarabadi A, Ramezankhani A, Barekati $\mathrm{H}$, Vejdani M, Shariatinejad K, Panahi R, et al. Prevalence of substance abuse among dormitory students of Shahid Beheshti University of Medical Sciences, Tehran, Iran. Int J High Risk Behav Addict. 2015;4(2):e22350. doi: 10.5812/ ijhrba.22350v2.

4. Ayatollahi SA, Mohammadpoorasl A, Rajaeifard A.
Predicting the stages of smoking acquisition in the male students of Shiraz's high schools, 2003. Nicotine Tob Res. 2005;7(6):845-51. doi: 10.1080/14622200500330233.

5. Mohammad Poorasl A, Vahidi R, Fakhari A, Rostami F, Dastghiri S. Substance abuse in Iranian high school students. Addict Behav. 2007;32(3):622-7. doi: 10.1016/j. addbeh.2006.05.008.

6. Gore FM, Bloem PJ, Patton GC, Ferguson J, Joseph V, Coffey $\mathrm{C}$, et al. Global burden of disease in young people aged 10-24 years: a systematic analysis. Lancet. 2011;377(9783):2093102. doi: 10.1016/s0140-6736(11)60512-6.

7. Gattamorta KA, Mena MP, Ainsley JB, Santisteban DA. The comorbidity of psychiatric and substance use disorders among Hispanic adolescents. J Dual Diagn. 2017;13(4):25463. doi: 10.1080/15504263.2017.1343965.

8. Khokhar JY, Dwiel LL, Henricks AM, Doucette WT, Green AI. The link between schizophrenia and substance use disorder: a unifying hypothesis. Schizophr Res. 2018;194:78-85. doi: 10.1016/j.schres.2017.04.016.

9. Meruelo AD, Castro N, Cota CI, Tapert SF. Cannabis and alcohol use, and the developing brain. Behav Brain Res. 2017;325(Pt A):44-50. doi: 10.1016/j.bbr.2017.02.025.

10. DuPont RL, Han B, Shea CL, Madras BK. Drug use among youth: national survey data support a common liability of all drug use. Prev Med. 2018;113:68-73. doi: 10.1016/j. ypmed.2018.05.015.

11. Moss HB, Chen CM, Yi HY. Early adolescent patterns of alcohol, cigarettes, and marijuana polysubstance use and young adult substance use outcomes in a nationally representative sample. Drug Alcohol Depend. 2014;136:5162. doi: 10.1016/j.drugalcdep.2013.12.011.

12. Yoon S, Kobulsky JM, Yoon D, Kim W. Developmental pathways from child maltreatment to adolescent substance use: the roles of posttraumatic stress symptoms and motherchild relationships. Child Youth Serv Rev. 2017;82:271-9. doi: 10.1016/j.childyouth.2017.09.035.

13. Whitesell M, Bachand A, Peel J, Brown M. Familial, social, and individual factors contributing to risk for adolescent substance use. J Addict. 2013;2013:579310. doi: 10.1155/2013/579310.

14. Alexopoulos C, Cho J. A moderated mediation model of parent-child communication, risk taking, alcohol consumption, and sexual experience in early adulthood. Arch Sex Behav. 2019;48(2):589-97. doi: 10.1007/s10508018-1181-z.

15. Lander L, Howsare J, Byrne M. The impact of substance use disorders on families and children: from theory to practice. Soc Work Public Health. 2013;28(3-4):194-205. doi: 10.1080/19371918.2013.759005.

16. Platter AJ, Kelley ML. Effectiveness of an educational and support program for family members of a substance abuser. Am J Fam Ther. 2012;40(3):208-13. doi: 10.1080/01926187.2011.585308.

17. Bandura A. Social Foundations of Thought and Action. Englewood Cliffs, NJ: Prentice-Hall; 1986. p. 23-8.

18. Bjornstad G, Montgomery P. Family therapy for attentiondeficit disorder or attention-deficit/hyperactivity disorder in children and adolescents. Cochrane Database Syst Rev. 2005(2):CD005042. doi: 10.1002/14651858.CD005042. pub2.

19. Dick DM, Adkins AE, Kuo SI. Genetic influences on adolescent behavior. Neurosci Biobehav Rev. 2016;70:198- 
205. doi: 10.1016/j.neubiorev.2016.07.007.

20. Van Loon LMA, Van de Ven MOM, Van Doesum KTM, Witteman CLM, Hosman CMH. The relation between parental mental illness and adolescent mental health: the role of family factors. J Child Fam Stud. 2014;23(7):120114. doi: 10.1007/s10826-013-9781-7.

21. Babadagi Z, Karabekiroglu KMZ, Ucar F, Say GN, Yuce M, Yildirim ZG. Associations between father temperament, character, rearing, psychopathology and child temperament in children aged 3-6 years. Psychiatr Q. 2018;89(3):589-604. doi: 10.1007/s11126-017-9556-1.

22. Goodman SH, Rouse MH, Connell AM, Broth MR, Hall CM, Heyward D. Maternal depression and child psychopathology: a meta-analytic review. Clin Child Fam Psychol Rev. 2011;14(1):1-27. doi: 10.1007/s10567-0100080-1.

23. Parker JS, Benson MJ. Parent-adolescent relations and adolescent functioning: self-esteem, substance abuse, and delinquency. Adolescence. 2004;39(155):519-30.

24. Branstetter SA, Low S, Furman W. The influence of parents and friends on adolescent substance use: a multidimensional approach. J Subst Use. 2011;16(2):15060. doi: 10.3109/14659891.2010.519421.

25. Hojjat SK, Golmakanie E, Norozi Khalili M, Smaili H, Hamidi M, Akaberi A. Personality traits and irrational beliefs in parents of substance-dependent adolescents: a comparative study. J Child Adolesc Subst Abuse. 2016;25(4):340-7. doi: 10.1080/1067828x.2015.1012612.

26. Mohammadi MR, Ahmadi N, Kamali K, Khaleghi A, Ahmadi A. Epidemiology of psychiatric disorders in Iranian children and adolescents (IRCAP) and its relationship with social capital, life style and parents' personality disorders: study protocol. Iran J Psychiatry. 2017;12(1):66-72.

27. Mohammadi MR, Alavi SS, Ahmadi N, Khaleghi A, Kamali $\mathrm{K}$, Ahmadi A, et al. The prevalence, comorbidity and sociodemographic factors of depressive disorder among Iranian children and adolescents: to identify the main predictors of depression. J Affect Disord. 2019;247:1-10. doi: 10.1016/j. jad.2019.01.005.

28. Kaufman J, Birmaher B, Brent D, Rao U, Flynn C, Moreci $\mathrm{P}$, et al. Schedule for affective disorders and schizophrenia for school-age children-present and lifetime version (K-SADS-PL): initial reliability and validity data. J Am Acad Child Adolesc Psychiatry. 1997;36(7):980-8. doi: 10.1097/00004583-199707000-00021.

29. Kaufman J, Birmaher B, Brent D, Rao U, Ryan N. The Schedule for Affective Disorders and Schizophrenia for School-Age Children. Pittsburgh: University of Pittsburgh Medical Center; 1996.

30. Ghanizadeh A. ADHD, bruxism and psychiatric disorders: does bruxism increase the chance of a comorbid psychiatric disorder in children with ADHD and their parents? Sleep Breath. 2008;12(4):375-80. doi: 10.1007/s11325-008-01839.

31. Millon T, Grossman S. MCMI-IV: Millon Clinical Multiaxial
Inventory Manual. Bloomington, MN: NCS Pearson; 2015.

32. Millon T, Davis R, Millon C, Grossman S. MCMI-III Manual. 3rd ed. Minneapolis, MN: Pearson Education Inc; 2006.

33. Blais MA, Holdwick DJ Jr, McLean RY, Otto MW, Pollack $\mathrm{MH}$, Hilsenroth MJ. Exploring the psychometric properties and construct validity of the MCMI-III anxiety and avoidant personality scales. J Pers Assess. 2003;81(3):23741. doi: 10.1207/s15327752jpa8103_06.

34. Sharifi AA, Moulavi H, Namdari K. The validity of MCMIIII (Millon, 1994) scales. Knowledge \& Research in Applied Psychology. 2008;9(34):27-38.

35. Wilson S, Durbin CE. Parental personality disorder symptoms are associated with dysfunctional parent-child interactions during early childhood: a multilevel modeling analysis. Personal Disord. 2012;3(1):55-65. doi: 10.1037/ a0024245.

36. Dessaulles A, Johnson SM, Denton WH. Emotion-focused therapy for couples in the treatment of depression: a pilot study. Am J Fam Ther. 2003;31(5):345-53. doi: 10.1080/01926180390232266.

37. Hair EC, Moore KA, Garrett SB, Ling T, Cleveland K. The continued importance of quality parent-adolescent relationships during late adolescence. J Res Adolesc. 2008;18(1):187-200. doi: 10.1111/j.1532-7795.2008.00556.x.

38. Sadock BJ. Kaplan \& Sadock's synopsis of psychiatry: behavioral sciences/clinical psychiatry. Available from: https://www.psychiatrist.com/read-pdf/11671/.

39. Barnow S, Spitzer C, Grabe HJ, Kessler C, Freyberger HJ. Individual characteristics, familial experience, and psychopathology in children of mothers with borderline personality disorder. J Am Acad Child Adolesc Psychiatry. 2006;45(8):965-72. doi: 10.1097/01.chi.0000222790.41853. b9.

40. Nickell AD, Waudby CJ, Trull TJ. Attachment, parental bonding and borderline personality disorder features in young adults. J Pers Disord. 2002;16(2):148-59. doi: 10.1521/pedi.16.2.148.22544.

41. Eddy JM, Leve LD, Fagot BI. Coercive family processes: a replication and extension of Patterson's coercion model. Aggress Behav. 2001;27(1):14-25. doi: $\quad 10.1002 / 1098-2337(20010101 / 31) 27: 1<14:: a i d-$ ab2>3.0.co;2-2.

42. Pagani LS, Tremblay RE, Nagin D, Zoccolillo M, Vitaro F, McDuff P. Risk factor models for adolescent verbal and physical aggression toward mothers. Int J Behav Dev. 2004;28(6):528-37. doi: 10.1080/01650250444000243.

43. Pellerin LA. Applying Baumrind's parenting typology to high schools: toward a middle-range theory of authoritative socialization. Soc Sci Res. 2005;34(2):283303. doi: 10.1016/j.ssresearch.2004.02.003.

44. Kumpfer KL, Fowler MA. Parenting skills and family support programs for drug-abusing mothers. Semin Fetal Neonatal Med. 2007;12(2):134-42. doi: 10.1016/j. siny.2007.01.003. 